\title{
BRANQUITUDE E RELIGIÃO: UMA ANÁLISE AUTOETNOGRÁFICA SOBRE SER UMA MULHER BRANCA NO CANDOMBLÉ
}

\author{
Priscila Kikuchi Campanaro*
}

\section{RESUMO}

A proposta do presente artigo é fazer uma análise autoetnográfica sobre a percepção da identidade branca e de todas as suas implicações interseccionais no campo religioso, a partir da experiência pessoal da autora: uma mulher branca iniciada no candomblé. Utilizando-nos da metodologia da autoetnografia esperamos contribuir com os estudos sobre branquitude, religião e interseccionalidade, evidenciando as tensões da intersecção entre gênero, raça e religião na vivência religiosa. $O$ intuito deste artigo não é, em hipótese alguma, reivindicar um suposto protagonismo de mulheres brancas nestes espaços religiosos, mas sim, discutir em que medida tais tensionamentos implicam em reflexões e atitudes práticas mediante o reconhecimento da identidade branca enquanto raça a partir da vivência no candomblé. Palavras-chave: Branquitude, religião, candomblé, gênero, raça.

\section{WHITENESS AND RELIGION: AN AUTOETHNOGRAPHIC ANALYSIS ON BEING A WHITE WOMAN IN CANDOMBLÉ}

\section{ABSTRACT}

The purpose of this article is to carry out an autoethnographic analysis of the perception of white identity, and all its intersectional implications in the religious field, based on the author's personal experience: a white woman initiated in candomblé. Using the methodology of autoethnography, we hope tocontributing to studies on whiteness, religion and intersectionality, highlighting the tensions of the intersection of gender, race and religion in religious experience. The purpose of this article is not, under any circumstances, to claim a supposed protagonism of white women in these religious spaces, but rather to discuss to what extent such tensions imply practical

* Doutora e Mestra em Ciências da Religião pela Universidade Metodista de São Paulo. Professora de Sociologia, Socióloga, Teóloga, 
reflections and attitudes through the recognition of white identity as a race based on their experience in the candomblé.

Keywords: Whiteness, religion, candomblé, gender, race.

\section{BLANCURA Y RELIGIÓN: UNA ANÁLISIS AUTOETNOGRÁFICA SOBRE SER MUJER BLANCA EN CANDOMBLÉ}

\section{RESUMEN}

El presente artículo tiene como propósito realizar un análisis autoetnográfico de la percepción de la identidad blanca, y todas sus implicaciones interseccionales en el campo religioso, a partir de la experiencia personal de la autora: una mujer blanca iniciada en el Candomblé. Utilizando el método autoetnografíco, pretende contribuir a los estudios sobre la blancura, la religión y la interseccionalidad, destacando las tensiones de la intersección de género, raza y religión en la experiencia religiosa. El propósito de este artículo no es, bajo ninguna circunstancia, reivindicar un supuesto protagonismo de la mujer blanca en estos espacios religiosos, sino discutir hasta qué punto tales tensiones implican reflexiones y actitudes prácticas a través del reconocimiento de la identidad blanca como raza basada en su experiencia en el candomblé.

Palabras clave: Blancura, religión, candomblé, género, raza.

\section{INTRODUÇÃO: SOBRE A ESCOLHA DO MÉTODO DA AUTOETNO- GRAFIA}

O método da autoetnografia se faz relevante na construção deste artigo por considerar a vinculação entre o campo de análise e a minha experiência pessoal enquanto mulher branca, iniciada no candomblé há um pouco mais de dois anos (Mary Jane SPINK, 2003).

Sobre o método, é importante destacar que se trata de um

[...] gênero da etnografia e método de pesquisa qualitativo [...] pode ser reconhecida como metodologia científica e crítica, capaz de desvendar, em sua maneira autorreflexiva, novos e profícuos caminhos para a pesquisa sociológica [...] a autoetnografia é um método que se sustenta e se equilibra em um "modelo triádico" baseado em três orientações: a primeira seria uma orientação metodológica - cuja base é etnográfica e analítica; a segunda, por uma orientação cultural - cuja base é a interpretação: a) dos fatores vividos (a partir da 
memória), b) do aspecto relacional entre o pesquisador e os sujeitos (e objetos) da pesquisa e c) dos fenômenos sociais investigados; e por último, a orientação do conteúdo - cuja base é a autobiografia aliada a um caráter reflexivo. (Silvio SANTOS, 2017, p. 214-218)

Diante do exposto, reconheço e me sinto responsável em articular experiências pessoais com aportes teóricos situados às temáticas pertinentes ao artigo, possibilitando assim a construção de um relato sobre um grupo de pertença, a partir de "eu mesma", a fim de, em certa medida compreender o mesmo enquanto experiência cultural (Silvio SANTOS, 2017. p. 220. Op. Cit. ELLIS, 2004). O método da autoetnografia é defendido nas áreas das Ciências Sociais desde a década de 1980 por intelectuais da área por rejeitar:

[...] a ideia de que os etnógrafos devem - ou podem - perpetuar ou se esconder atrás de um "ideal de objetividade", esses pesquisadores passaram a se identificar como parte de seus estudos, muitas vezes escrevendo histórias sobre o processo de investigação e, por vezes, sobre suas experiências pessoais. (Silvio SANTOS, 2017, p.222)

Apesar de se apresentar como uma proposta promissora,há também críticas em relação à sua legitimidade, fato este que não pode ser ignorado:

O professor de filosofia Vincent F. Hendricks, da Universidade de Copenhague, na Dinamarca, por exemplo, diz que a autoetnografia não cumpre os pré-requisitos necessários para que seja aceita como ciência. Para ele, estudos autoetnográficos não atendem a uma série de condições que garantem confiabilidade a investigações científicas, entre elas, a possibilidade de ser testados ou previstos, de ser representativos ou permitir extrapolações'.

Mesmo tendo ciência de tais críticas e sabendo dos riscos envolvidos no uso do método, acredito que a autoetnografia tem ajudado a ampliar o entendimento sobre a questão racial e os estudos de gêne-

'Selfie acadêmica': Os pesquisadores que usam a si mesmos como base de estudos.BBC News Brasil. Disponível em: <https://www.bbc.com/portuguese/geral-40006132>. Acesso em 11 out.2021. 
ro, evitando as definições rígidas e, dessa forma, tornando o debate sobre os temas mencionados mais significativos. O que me impulsiona a utilizar esse tipo de método é o fato do mesmo possibilitar pensar e desenvolver uma análise sobre a intersecção religião e raça a partir de um acontecimento que me transformou significativamente como pessoa (Silvio SANTOS, 2017) e, consequentemente, como pesquisadora.

Cabe acrescentar que, justificada a relevância do uso da experiência pessoal, é primordial também a compreensão de que a mesma não existe isoladamente, portanto a pesquisa se utilizará também de referenciais que apresentam facetas dessa experiência sociocultural (Silvio SANTOS, 2017) da maneira mais ampla possível.

Explicitada a escolha do método é possível, então, descrever de que maneira o mesmo se apresentará no decorrer do artigo. No começo de cada tópico, um trecho de um relato pessoal sobre a minha vivência no candomblé será exposto, e em seguida do mesmo, apresentarei uma análise deste fragmento a partir de aportes teóricos que abordam questões envolvendo, gênero, raça e religião, com o objetivo de evidenciar as implicações raciais de ser uma mulher branca no/do candomblé.

\section{OS ESTUDOS SOBRE BRANQUITUDE NO BRASIL: UM PANORAMA DO ESTADO DA QUESTÃO}

No ano de 2019, depois de frequentar, desde 2016, um terreiro de candomblé localizado na cidade de Itapecerica da Serra - SP, decidi me submeter ao processo de iniciação na religião. Essa decisão foi tomada considerando dois fatores que considero cruciais: 1) a vinculação com as pessoas que frequentam este espaço, pois o sentimento de pertencer a uma comunidade muito acolhedora e amorosa me fez criar um vínculo afetivo significativo e influenciou, em parte, a tomada dessa decisão; 2) por conta de experiências de caráter subjetivo ocorridos em momentos de contato com o sagrado neste espaço, que vieram a ter uma importância muito grande na minha vida pessoal. Durante o processo de preparação para esse momento de me submeter à iniciação, a questão racial não foi pensada. Sempre me identifiquei como uma mulher branca e o fato de existirem pessoas de pele clara neste espaço religioso fez com que eu não sentisse, em nenhum momento, alguma sensação de desconforto... 
Abordar a questão da percepção da identidade racial, ou da falta dela, enquanto uma mulher branca recém-iniciada no candomblé, implica em procurar aportes teóricos contidos nos estudos sobre branquitude, pois os mesmos me possibilitam evidenciar em que medida essa condição mencionada acima, possibilitaevidenciar os privilégios concedidos à identidade branca e as tensões em relação à experiência religiosa com os marcadores históricos, sociais e culturais da sociedade brasileira.

Na primeira parte do meu relato, onde descrevo, em linhas gerais, como se deu a decisão da minha adesão religiosa, é possível verificar um desses privilégios brancos. $O$ fato de que outras presenças brancas neste espaço religioso me permitiram não sentir qualquer desconforto evidencia que, para pessoas brancas, todos os espaços, mesmo aqueles historicamente representados como resistência do povo negro no Brasil, estão abertos e podem ser ocupados pelo corpo branco. Segundo os estudos sobre branquitude no Brasil, a identidade branca não é compreendida enquanto raça, mas sim, como um padrão humano e, por isso, deve ser aceito em qualquer espaço. O não reconhecimento do branco enquanto raça, segundo estes estudos, configura uma estratégia de manutenção de poder, privilégios e vantagens exclusivos para pessoas brancas no universo racial brasileiro. Em linhas gerais, entende-se por branquitude uma forma de poder, que se manifesta a partir de lugares de privilégios simbólicos, subjetivos e materiais, e que, portanto, colaboram com a reprodução do preconceito racial e do racismo (Lourenço CARDOSO, 2011).

No Brasil, eles tiveram seu início no final da década de 1950 e começo da década 1960, com Alberto Guerreiro Ramos, o primeiro intelectual negro no Brasil a propor os estudos sobre identidade branca no país. Em sua primeira obra, Patologia Social do Branco, o autor diz que a minoria branca no país garante a espoliação dos/as não brancos/ as pela violência e pela construção de estereótipos, fazendo com que a negritude seja constantemente rejeitada e a branquitude desejada (apud Lourenço CARDOSO, 2011).

Dando um salto significativo no tempo, chegamos aos anos 2000, onde Edith Piza (2002) aborda o tema a partir do conceito da "Porta de Vidro". Segundo Edith Piza (2002), esse conceito se refere ao momento em que a pessoa branca se depara com a sua branquitude enquanto 
identidade racial. Quando isso acontece, essa pessoa sente um impacto semelhante ao se chocar com uma porta de vidro. Com esta analogia, Piza sustenta a ideia da "invisibilidade" da raça branca, considerada controversa. Para estudiosos como Lourenço Cardoso (2011) o conceito da "Porta de Vidro" pode reforçar a noção de que a branquitude é uma ideia fantasiosa, o que possibilita a esse grupo não questionar assuas vantagens.

Apesar do tema da branquitude ter ganhado uma significativa importância no Brasil nos últimos tempos, as investigações sobre o tema aparecem de maneira implícita em pesquisas acadêmicas, sendo que o que mais se encontra são trabalhos voltados aos estudos sobre pertença étnica de grupos brancos como bem coloca Lourenço Cardoso (2011) na tabela a seguir.

Tabela 2 - O tema branquitude implícita nas produçóes acadêmicas brasileiras

\begin{tabular}{|l|l|l|l|l|l|}
\hline Universidade & Ano & Grau & Subárea & Títulos & Autoria \\
\hline 1) UERJ (Sudeste) & 2002 & $\mathrm{M}$ & História & $\begin{array}{l}\text { Os “Auslanddeutsche" no Brasil. As colônias Alemâs no } \\
\text { contexto das Relaçóes Brasil-Alemanha. Um olhar sobre } \\
\text { o Vale do Itajaí-Açu (1937-1945). }\end{array}$ & $\begin{array}{l}\text { Mônica Velloso } \\
\text { Azevedo }\end{array}$ \\
\hline 2) UFRJ (Sudeste) & 2004 & $\mathrm{M}$ & História & $\begin{array}{l}\text { Conflitos, crimes e resistência: uma análise dos } \\
\text { alemáes e teuto-descendentes através de processos } \\
\text { criminais (Juiz de Fora - 1858/1921). }\end{array}$ & $\begin{array}{l}\text { Deivy Ferreira Car- } \\
\text { neiro }\end{array}$ \\
\hline 3) UFRGS (Sul) & 2001 & $\mathrm{M}$ & $\begin{array}{l}\text { Comuni- } \\
\text { caçáo }\end{array}$ & $\begin{array}{l}\text { O desenho de humor no resgate da identidade cultu- } \\
\text { ral análise de personagens }\end{array}$ & $\begin{array}{l}\text { Augusto Franke } \\
\text { Bier }\end{array}$ \\
\hline 4) UFRGS (Sul) & 2005 & $\mathrm{D}$ & História & $\begin{array}{l}\text { A trajetória de uma liderança étnica: J. Aloys Friedrichs } \\
\text { (1869-1950). }\end{array}$ & $\begin{array}{l}\text { Haike Roselane Kle- } \\
\text { ber da Silva }\end{array}$ \\
\hline 5) UFSC (Sul) & 2002 & $\mathrm{M}$ & $\begin{array}{l}\text { Educaçáa } \\
\text { fisica }\end{array}$ & $\begin{array}{l}\text { A cultura popular e as atividades rítmicas: um estudo de } \\
\text { caso em uma comunidade de raiz étnica germânica. }\end{array}$ & $\begin{array}{l}\text { Célia Guima-ráes } \\
\text { Perini }\end{array}$ \\
\hline 6) UFSC (Sul) & 2004 & $\mathrm{M}$ & $\begin{array}{l}\text { Ciências } \\
\text { Humanas }\end{array}$ & $\begin{array}{l}\text { Representaçóes sociais e etnia: um retrato interdisciplinar } \\
\text { de Escola Agrícola. }\end{array}$ & $\begin{array}{l}\text { Márcia Santos de } \\
\text { Souza }\end{array}$ \\
\hline 7) UFSC (Sul) & 2001 & $\mathrm{M}$ & História & $\begin{array}{l}\text { Alemáes em Lages: uma trajetória de conflitos e alianças } \\
\text { guardadas pela memória. }\end{array}$ & $\begin{array}{l}\text { Branco, Juçara de } \\
\text { Souza Castello }\end{array}$ \\
\hline
\end{tabular}

(CARDOSO, 2008)

É importante destacar que a primeira tese defendida no Brasil sobre o tema da branquitude foi de Maria Aparecida da Silva Bento, onde a mesma desenvolveu o conceito do Pacto-Narcísico. Segundo Maria Aparecida Bento (2002), a persistência das desigualdades sociais/ raciais no país são também consequência de pactos realizados entre os/ as brancos/as que se unem para defender seus privilégios raciais (Lourenço CARDOSO, 2011). Em linhas gerais, a mesma diz que a branquitude representa a pertença étnico-racial atribuída ao/à branco/a, que Ihes 
confere poder. A branquitude é, portanto, constituída pela sua condição ideal de ser o padrão humano, o que lhe confere legitimidade para se sentir acima de "outros seres" (Grada KILOMBA, 2019).

O fenômeno do Pacto-Narcísico pode ser verificado no primeiro fragmento do meu relato no início deste tópico, onde menciono que a presença de outras pessoas brancas naquele espaço religioso de candomblé, antes de eu passar pelo processo de iniciação, fez com que eu me sentisse confortável e não sentisse nenhum tipo de tensionamento quando decidi pertencer a espaços historicamente e socialmente constituídos como resistência negra no Brasil.

\section{O CANDOMBLÉ NO BRASIL: EMBRANQUECIMENTO E BRANQUITUDE}

Passado o período de recolhimento por conta da iniciação, e de preceito exigido após esse processo, comecei a pensar sobre ser branca e ser candomblecista. Esse "start" foi provocado através de leituras diversas que comecei a fazer sobre feminismo decolonial, feminismo negro. Como sou pesquisadora destes temas, estou sempre em busca e em contato com leituras que contenham estes temas. As leituras que mais me chamaram a atenção para isso foram,especificamente, de livros e artigos escritos por mulheres negras de candomblé, como Carla Akotirene, Lélia Gonzalez, Sueli Carneiro e Djamila Ribeiro. Os conceitos-denúncias, como gosto de chamá-los, que as autoras fazem em relação à branquitude, começaram a tensionar a minha relação com a religião, principalmente no que se refere à questão da ancestralidade. Comecei a pensar nessa questão, e isso foi me ajudando a enxergar o fato de ser branca como uma raça...

O candomblé no Brasil é a expressão da resistência ancestral da negritude em uma sociedade historicamente racista. É um sistema multifacetado que, através da prática cotidiana, preza pela perpetuação de heranças africanas ancestrais. É um microcosmo de múltiplas referências onde a espiritualidade é inseparável das práticas comunitárias (Jonas FRANÇA, 2018). É sabido que a religião é uma das instituições sociais responsáveis por promover processos de socialização (Peter BERGER, 2013), portanto, o espaço religioso do candomblé também tem, como potência, a possibilidade de fazer com que seus adeptos aprendam mais 
sobre as populações afrodiaspóricas, bem como suas cosmovisões, e questões relacionadas à raça.

Diante disso, pode-se dizer que espaços religiosos também são educativos, e no contexto do candomblé, em suas práticas, o processo de educação étnico-racial é também uma problemática política (Luiz RUFINO, 2019). Há então, no contexto do candomblé brasileiro, o que se tem chamado de educação de axé que:

[...] compreende-se como os processos educativos vividos nos cotidianos dessas populações, uma espécie de habitus experienciado no tempo/espaço dos contextos afro-religiosos. Essas formas de educação praticadas nesses contextos educativos redimensionam a problemática educativa em relação à diversidade, revelando modos de educação como cultura (Luiz RUFINO, 2019, p. 9).

Iniciei o segundo tópico deste artigo com mais um fragmento do meu relato pessoal, e nele é possível identificar que a minha tomada de consciência ancestral branca só pôde ser realizada por essa educação de axé, que trouxe à tona não somente questões ligadas à espiritualidade, mas de minha história pessoal e o quanto ela está vinculada ao racismo. Vale destacar aqui que a educação de axé perpassa o cotidiano da vida religiosa dentro do candomblé, e portanto, coube a mim, pessoa branca inserida neste contexto religioso, permitir-me afetar pela educação de axé e portanto, tomar consciência da minha identidade branca. A educação de axé não pode ser entendida como um trabalho a ser cobrado por candomblecistas negros/as de "ensinar" as pessoas brancas candomblecistas a não serem racistas.

A identificação racial dos adeptos do candomblé no Brasil, segundo os dados do CENSO referente ao ano de 2010 mostram que 39,3\% são pardos, 30,2\% são brancos e $29,1 \%$ são pretos. No caso da adesão na cidade de São Paulo, segundo esse mesmo CENSO, as porcentagens se apresentaram da seguinte maneira: $60,6 \%$ são brancos, $25,5 \%$ são pardos e $13,1 \%$ são pretos. Diante de tais dados fica evidente que existe um processo de embranquecimento ${ }^{2}$ do candomblé no Brasil, e mais

Por embranquecimento do candomblé entende-se que o termo se refere à presença crescente de pessoas de pele branca dentro dos terreiros, sendo assim, esse processo, não necessariamente, evoca a branquitude. 
especificamente na cidade de São Paulo. Diante do que foi exposto até então, é importante destacar três pontos sobre a inserção de pessoas brancas no candomblé no Brasil: 1) não é um fenômeno recente; 2) ocorre dentro de várias tradições e famílias de candomblé e 3) por si só, não traz problemas; pessoas brancas podem advir a partir de posturas que negam o antagonismo existente entre cultura de branquitude e valores religiosos afro-ameríndios (Jonas FRANÇA, 2018).

Sobre o terceiro e último ponto, é importante destacar que o mesmo se refere a uma branquitude crítica, termo utilizado pelos estudos de branquitude no Brasil para se referir a: "indivíduos ou grupo de brancos que desaprovam "publicamente" o racismo..." Porém, Lourenço Cardoso faz um adendo importante nessa definição, que pode ou não se manifestar entre branquitudes ditas críticas: “...no entanto no espaço privado, revela-se racista... não critica de forma geral o privilégio branco, vive sob o princípio da igualdade e sob o signo da modernidade" (Lourenço CARDOSO, 2017, p. 33, 34 e 35). Portanto, falar sobre branquitude no contexto do candomblé implica lidar não apenas com o processo de embranquecimento, mas também com a complexidade dos limites de uma branquitude crítica, que se posiciona contra o racismo por ser de candomblé, porém não abre mão dos privilégios raciais da sua identidade branca dentro deste espaço.

Essa complexidade fica evidente em pesquisa já bem antiga de Rita Amaral e Vagner Silva (1993), na qual se identifica que as divindades religiosas pertencentes ao imaginário afro-brasileiro são classificadas racialmente a partir da compreensão da personalidade e dos poderes das divindades do Candomblé, colocados dentro de uma estrutura hierárquica do mais importante para o menos importante. Segundo o pesquisador e a pesquisadora, Ogum e Xangô seriam orixás considerados mais próximos da realidade das pessoas negras porque são fortes e impetuosos. Já Oxossi seria mais próximo das pessoas mulatas, pela relação que se faz com os caboclos, e lemanjá e Oxalá seriam brancos porque são criadores do mundo e no senso comum, acima de todos os outros orixás (Rita de Cássia AMARAL; Vagner SILVA, 1993).

Essa classificação evidencia que o processo de branqueamento das divindades afro-religiosas de acordo com uma suposta "hierarquia de 
poderes" se baseia em lógicas históricas de uma cultura branca colonial que está acima de todos. A partir dela é possível verificar valores da branquitude brasileira incorporados ao universo religioso afro-brasileiro, atribuindo aos/às Orixás criadores da humanidade a cor e a identidade branca, os/as demais, se aproximam mais das identidades não brancas, com o que se reforçam os estereótipos construídos com base na classificação colonial de raça.

\section{1. O "ESCURECIMENTO" ESPIRITUAL DAS PESSOAS BRANCAS NO CANDOMBLÉ: RELIGIÃO E MITO DA DEMOCRACIA RACIAL}

Em relação à ancestralidade, teve um momento em que parei e pensei: Vamos lá, vamos pensar na sua ancestralidade pessoal. Quem são seus ancestrais, o que eles eram, o que você carrega deles? Ao fazer esse exercício eu percebi que venho de um contexto familiar muito racista, $e$ que se muitos/as deles/as ainda estivessem vivos/as, nunca aceitariam o fato de eu ser candomblecista. Lembrei de atitudes e histórias de muito desprezo em relação às pessoas negras, e principalmente da religiosidade afro-brasileira, vindos das/os meus/minhas ancestrais. Tomar essa consciência foi determinante para que eu entendesse que eu nunca poderia equiparar a minha vivência enquanto candomblecista à de uma pessoa negra. Que eu deveria ter uma autoconsciência ancestral responsável e reconhecer que sou fruto de uma criação racista, e que cabe a mim, uma mulher branca, me responsabilizar em fazer da minha vivência religiosa um processo de "cura" da minha ancestralidade racista. Diante dessa consciência, comecei a seguir o perfil de pessoas que falavam sobre candomblé ou sobre religião dos orixás no Instagram, fossem elas pessoas brancas ou não. Uma dessas pessoas escreveu um relato que me chamou a atenção, em uma de suas postagens ele dizia que, mesmo sendo branco, o fato de ter renascido para o orixá, o fazia parte de uma família ancestral africana, portanto, sua linhagem ancestral, a partir daquele momento era africana. Isso deu um certo nó na cabeça. Eu preferi entender que ele estava falando a partir de uma dimensão espiritual, o que até faz sentido, mas me questionei até que ponto isso também não poderia ser uma desculpa para desresponsabilizar pessoas brancas pertencentes a religiões de matriz africana por não refletirem sobre branquitude... 
Em mais um trecho do meu relato, apresento outro tipo de discurso evocado nas redes sociais, neste caso o Instagram, que evidencia um processo de "enegrecimento" da ancestralidade espiritual de pessoas brancas pela adesão religiosa ao candomblé. Algumas pessoas brancas compreendem que ao passarem pelo processo de iniciação em determinado orixá, e, ao torna-se filho/a do/a mesmo/a, torna-se então parte da vasta família ancestral negra do/a mesmo/a. No que tange às relações raciais e inter-raciais, e exponho isso no meu relato como vocês puderam ler, entendo que esse tipo de compreensão pode levar a pessoa branca, no caso aquela que se inicia no candomblé, a não perceber a sua identidade branca enquanto raça, mesmo que tal compreensão seja feita apenas em nível subjetivo (espiritual).

Diante do exposto até então, percebemos uma tensão muito complexa entre os processos de 1) "branqueamento" de orixás considerados/as mais importantes e 2) "escurecimento" da ancestralidade branca pelo viés da iniciação. Isso nos revela duas leituras e percepções; no primeiro caso, de uma classificação racial demarcada pela noção de superior-inferior e, no segundo, da não percepção da identidade branca como raça, fazendo com que a mesma até seja eliminada a partir de justificativas espirituais, entendidas como inquestionáveis.

Esse "branqueamento" e "escurecimento" são dinâmicas que atestam o fato de que a religião é um empreendimento social humano (Peter BERGER; 2013; Pierre BOURDIEU, 2013) e que, portanto, poderá ser moldada "à imagem e semelhança" da identidade branca para perpetuar seus privilégios de não responsabilização pelo racismo, visto que a sociedade brasileira ainda respira os ares do mito da democracia racial ${ }^{3}$.

\section{SACERDOTISAS E YABÁS: QUESTIONANDO A CATEGORIA GÊNERO E A BRANQUITUDE FEMININA E FEMINISTA}

Apesar de ter tido um pouco de contato com a umbanda quando eu era criança, meu maior tempo de vivência religiosa, antes de frequentar o

3 Mito de dominação que impede a consciência objetiva do racismo e o conhecimento direto de suas práticas concretas. O mito da democracia racial se baseia na crença historicamente construída sobre a miscigenação (O racismo brasileiro na obra de Lélia Gonzalez. Carta Capital. Disponível em: <https://www.cartacapital.com.br/blogs/sororidade-em-pauta/o-racismo-brasileiro-na-obra-de-lelia-gonzalez/>. Acesso 11 out.2021). 
candomblé e ser iniciada, foi em igrejas evangélicas. Dos 12 aos 25 anos fui muito ativa nestes espaços religiosos. Tudo que eu sabia sobre fé e religião se baseava no que eu aprendia enquanto cristã evangélica e protestante. Quando comecei a estudar teologia, conheci um centro ecumênico que promove diversos cursos sobre religião e diálogo inter-religioso e foi essa experiência que ampliou e transformou o meu olhar em relação a tais questões. Foi nesse espaço também que conheci a minha então lyalorixá. Nesse período de estudos de Teologia me aproximei dos estudos sobre gênero e religião, eu gostei tanto que acabei continuando meus estudos depois da graduação no Programa de pós-graduação em Ciências da Religião, construindo meu projeto de mestrado nessa área. Concomitante à minha carreira acadêmica, eu trabalhava como voluntária neste centro ecumênico que mencionei e, com isso, fui conhecendo mais o candomblé. Uma das coisas que mais me chamou atenção enquanto aprendia mais sobre o candomblé foi sobre o que as Orixás femininas representavam para as mulheres do candomblé e o quanto elas eram a força e a inspiração de vida da minha lyalorixá, uma mulher negra e sacerdotisa dessa religião.

As mulheres são maioria em diversos espaços religiosos (Laila ROSA, 2010. Op. Cit. Maria José ROSADO-NUNES, 2005). No caso das religiões de matriz afro-brasileira, estes espaços por muito tempo apresentaram um perfil de mulheres, em sua maioria negras e, somente de maneira eventual, brancas (Laila ROSA, 2010). Porém no contexto da cidade de São Paulo, reportagem do ano de 2016 no site do Jornal Estadão revela que brancos são mais de $60 \%$ dos adeptos de religiões de matriz africana na cidade e aponta que, de acordo com os dados de uma pesquisa realizada pela Secretaria Municipal de Promoção da Igualdade Racial, 60,6\% dos adeptos e adeptas de religióes de matriz africana são brancos, sendoque a maior parte é composta por mulheres, $56,36 \%$ contra $43,63 \%$ de homens ${ }^{4}$. Diante destes dados é perceptível a necessidade e emergência de um olhar a partir da crítica à branquitude desse contingente.

Felipe Resk. Brancos são mais de 60\% dos adeptos de religiões afro-brasileiras em São Paulo.' Site Estadão, 23 de dezembro de 2016. Disponível em <https://sao-paulo.estadao.com.br/noticias/ geral,brancos-sao-maioria-nas-religioes-afro-brasileira-diz-estudo,10000096203> Acesso em 30 de maio de 2021 
No fragmento do meu relato pessoal é possível identificar que minha admiração inicial pelo candomblé se deu por conhecer um pouco mais sobre as orixás femininas que, além de inspirar, representavam o lugar da força das sacerdotisas e das mulheres negras dessa religião. Sobre isso é importante acrescentar que o candomblé apresenta um padrão de gênero diferenciado das estruturas de poder cristãs, especialmente no que se refere à presença do feminino tanto na sua cosmologia, quanto em instâncias de poder. Diferente do cristianismo, especialmente na sua expressão católica, mulheres podem se tornar lideranças dentro dos terreiros (J. Lorand MATORY, 2008). Este fato despertou o interesse de pesquisadoras como a antropóloga Ruth Landes 5 , que publicou a obra A cidade das mulheres no candomblé, no início do século XX. Nesta obra, Landes enfatiza o caráter matriarcal do Candomblé, e afirma que o mesmo é uma forma não europeia de emancipação feminina, em suma: é o matriarcado em ação. (J. Flávio FERREIRA, 2016).

Em relação à análise de Landes, e também ao fragmento do meu relato no começo deste tópico, é preciso fazer algumas considerações importantes. Como já foi mencionado neste artigo, o candomblé no Brasil é considerado um sistema multifacetado que, através da prática cotidiana preza pela perpetuação de heranças africanas ancestrais (Jonas FRANÇA, 2018). Portanto, pensar as representações de feminino e masculino a partir da noção de gênero ocidental pode gerar alguns equívocos, porque os atributos dos orixás não são legitimados nem reforçados por serem masculinos ou femininos, mas sim, porque representam uma força da natureza necessária para a vida enquanto humanidade.

Na religião iorubá, em dois, de seus três ${ }^{6}$ pilares Olodumare (Deus-Supremo), e Orixás (divindades), não é feita nenhuma distinção de gênero. No primeiro pilar, não há nenhuma identidade de gênero atribuída e, no segundo, referente às manifestações dos atributos do ser supremo, a distinção dessas divindades não é feita por critérios de

5 Ruth Landes foi uma antropóloga estadunidense. Formou-se pela Universidade de Columbia, em Nova Iorque, influenciada por Franz Boas. Ela foi uma pioneira nos estudos sobre as mães-de-santo do Candomblé em Salvador.

6 O terceiro pilar seriam dos ancestrais (Egungún) que são venerados por membros da linhagem (Oyeronké OYEWUMI, 2021). 
gênero, mas sim referente à sua energia; por exemplo, Xangô e Oyá são conhecidos por sua ira e não pensados em termos de gênero (Oyeronké OYEWUMI, 2021). Portanto, deve-se ter cautela com análises que tendem a priorizar gênero, pois elas evidenciam uma produção e reprodução de epistemologias a partir de uma experiência generificada dentro do contexto ocidental (Oyeronké OYEWUMI, 2020) e que no contexto yorubá não tem a mesma importância.

Diante disso, a dimensão da interseccionalidade se faz necessária dentro dessa discussão, isto é, é mais do que necessário encruzilhar as dimensões. No caso da cosmovisão iorubá e da experiência das religiões africanas neste continente, gênero não informa relações de opressão entre mulheres e homens da mesma forma que informa no ocidente e na cosmovisão cristã. No caso do Brasil, faz sentido fazer algumas ressalvas em relação à questão por conta da imposição cultural que o cristianismo consegue estabelecer em diversas instituições sociais, que pode, em alguns casos, não isentar os terreiros de candomblé7. E é aí que a interseccionalidade, uma ferramenta ancestral criada pelas mulheres negras (Carla AKOTIRENE, 2019), tem a capacidade de encruzilhar realidades, questionando a branquitude e as categorias de análise cristalizadas no ocidente.

Diante do exposto, vale destacar que a figura das mulheres negras no candomblé possui um significativo e importante espaço em diversas publicações voltadas para o tema do candomblé e o poder feminino (Teresinha BERNARDO, 2005; Kiusam OLIVEIRA, 2008; Gilmara MARIOSA; Cláudia MAYORGA, 2018). Já as mulheres brancas por sua vez, ainda são vistas como minoria nestes espaços e, por isso, questões de gênero interseccionadas com os debates sobre branquitude ainda não são muito recorrentes. Sobre isso, gostaria de reafirmar que a proposta deste artigo não é, de maneira alguma reivindicar, e muito menos evocar, um suposto "protagonismo" de mulheres brancas no candomblé, mas sim,

Sobre essa discussão, vale a leitura da tese de doutorado de Nilza Menezes (2012) publicada em livro sob o título: A violência de gênero nas religiões afro-brasileiras, onde a autora apresenta o resultado de sua pesquisa com imersão no campo religioso afro-brasileiro, na cidade de Porto Velho, Rondônia, e outras localidades. Em sua pesquisa ela fundamenta teóricamente suas análises a partir do eixo relacional gênero - sexo, etnia e divisão do trabalho - desvelando a ocorrência de violências simbólicas que permeiam as relações sociais neste contexto. 
a partir da minha experiência pessoal, lançar pressupostos que possibilitem discutir de maneira mais ampla as implicações interseccionais que envolvem a identidade branca no espaço do candomblé.

A necessidade de levantar esse debate se justifica não somente pelos poucos trabalhos sobre o assunto, mas porque é cada vez mais emergente discutir o que vem a ser e como se manifesta a branquitude na experiência feminina. Em certa medida, ela não difere da masculina, que tem como característica ser neutralizada e desracializada (Dieuwertje HUIJG, 2007). Porém essa neutralização e desracialização também podem ser reforçadas por pressupostos feministas, usados por mulheres que ainda insistem em dizer que a condição de sujeição e inferioridade em relação aos homens é uma opressão universal acima de qualquer outra e que somente a superação da mesma é capaz de eliminar todas as outras.

Mais do que a ideia, o reforço da mesma através de práticas e discursos que colocam em segundo plano, ou apenas como algo "transversal", a questão da raça só explicitam que as mulheres brancas, bem como os homens brancos, foram socializadas/os com um sentimento de superioridade racial. Portanto mulheres brancas, feministas ou não, sistematicamente se favorecem e se tornam cúmplices ativas do racismo, mesmo sendo os estudos feministas precursores de um olhar das margens (Lia SCHUCMAN, 2020).

As mulheres brancas não se veem como parte dos sistemas hegemônicos, como o racismo, que sustentam sistemas estruturantes da hegemonia branca (Dieuwertje HUIJG, 2007). Nesse contexto vale destacar que, no Brasil, feministas negras vêm denunciando com veemência a branquitude feminina e porque não, feminista também (Lélia GONZALEZ, 2020; Sueli CARNEIRO, 2019; Carla AKOTIRENE, 2019). Portanto, enquanto mulher branca candomblecista, a educação de axé implica também em questionar e relativizar a centralidade de gênero nas minhas análises e percepções cotidianas que se articulam com os meus interesses enquanto pesquisadora. 


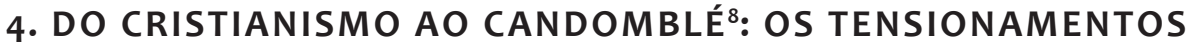 ENTRE A EXPERIÊNCIA EVANGÉLICA E PROTESTANTE, COM AS DINÂMICAS COMUNITÁRIAS DO CANDOMBLÉ)}

Nesses meus dois anos e mais um pouco como candomblecista, sinto que me falta aprender muito, e esse é um dos fatores com os quais eu mais tenho dificuldade de lidar. O processo de aprendizado dentro da religião em grande parte se dá na prática, no cotidiano da vida no ilê (casa). Eu até posso ler muitos livros, assistir muitos vídeos, seguir referências e lideranças do candomblé nas redes sociais, e aprender muitas coisas. Posso dizer que esse processo de reconhecimento da branquitude, em grande medida foi impulsionado pelo conhecimento a que tive acesso nestes meios e acredito que isso é muito importante. Mas é no cotidiano da vivência na comunidade que a gente aprende sobre candomblé. $O$ fato de considerar isso uma dificuldade minha, pessoalmente, se justifica pela forma como eu aprendi a viver religião no cristianismo de vertente evangélica e protestante. Nesse contexto, você meio que pode "se virar" sozinha, é uma tendência hoje em dia você ser cristão sem igreja. No candomblé não dá pra ser assim. Tem coisas que não são possíveis de se fazer sozinha, tem coisas que você precisa de pelo menos uma outra pessoa ou/e da comunidade toda, senão o axé não circula, e tem horas que eu me pego em tensão com isso. A situação de pandemia por conta da Covid nos anos de 2020 e 2021 e, somado a isso, um problema sério de saúde com a minha mãe, me privou de frequentar o ilê. Atualmente estou há muito tempo sem ir porque preciso ainda cuidar um pouco mais da minha mãe. Sei que os/as orixás entendem a minha situação, mas sinto que estou perdendo muito sobre esse aprendizado de não ser sozinha, e sim, ser comunidade. Eu sei que muitas pessoas acham lindo, como eu sempre achei, quando ouvia essas coisas, mas na prática, ainda mais se você foi educada religiosamente em outro contexto religioso, é muito difícil.

A propósito do título desse tópico é importante destacar o artigo de Ozaias da Silva Rodrigues (2019) Do evangelho ao candomblé: a inserção de um pesquisador evangélico nas religiões de matriz africana, que aborda essa temática a partir da sua experiência pessoal enquanto doutorando de antropologia, evangélico, que se insere no campo das religiões de matriz africana para desenvolver sua pesquisa. Apesar de tratar do tema por uma perspectiva distinta da deste artigo, vejo como necessária a menção do mesmo. 
Através da minha experiência pessoal como mulher branca iniciada no candomblé, me foi possível identificar diversos traços da branquitude, não só no que tange à questão da ancestralidade racista da minha família biológica, mas também, no que tange à minha maneira de viver religião. Pessoas brancas não são cobradas no coletivo, isto é, elas não respondem enquanto grupo, mas sim, enquanto indivíduo, logo suas ações são tratadas individualmente (Lia SCHUCMAN, 2020) o que, em certa medida, explica a maneira na qual fui educada religiosamente. $\mathrm{E}$ o fato de estar, agora, inserida em outro contexto religioso, que pressupõe que a vida comunitária é um dos pilares mais importantes da fé, essa situação me proporciona tensões.

Minha vivência religiosa no contexto cristão evangélico e protestante, apesar de valorizar a presença no espaço religioso, também tinha um discurso enfático que reforçava a ideia do sacerdócio universal ${ }^{9}$, que tem como princípio a noção de que cada cristão é membro do corpo de Cristo e que, por isso, está no mesmo patamar diante de Deus, não necessitando de intermediação. Portanto, nesse contexto cristão em específico, a religião passa a ser entendida como uma experiência autônoma, onde eu me sentia confortável em escolher como iria vivenciar minha fé, fosse em comunidade ou não ${ }^{10}$. Essa racionalização da religião, e mais especificamente da cristã, confere a ela um caráter de autonormatividade onde a experiência religiosa é "dotada de tendências e interesses próprios” (Pierre BOURDIEU, 2013, p. 101).

Diante disso, entendo a compreensão dessa tensão, passado evangélico/protestante e presente candomblecista, como um importante impulso para entrar num processo de letramento racial"1 a partir da minha

9 Vale destacar que esse conceito é um dos pilares da teologia reformada. É também considerado uma evolução do pensamento de Lutero, interpretado pela Igreja Católica Apostólica Romana como uma afronta à hierarquia clerical já estabelecida e consolidada (Marcelo LANFRANCHI, 2019)

10 Sobre essa tema, faz-se importante mencionar que há uma categoria censitária que categoriza pessoas que não frequentam instituições religiosas como "sem religião", embora os mesmos estejam agregados nesta única categoria, aparentemente secularizada, não se pode ignorar o fato de que os mesmos, podem ser constituídos por tipos com características e cosmovisões religiosas distintas, o que suscita então a necessidade de uma classificação mais precisa (Denise RODRIGUES, 2007).

11 TWINE, France W. A white side of black Britain: the concept of racial literacy. Disponível em: < https://www.tandfonline.com/doi/abs/10.1080/0141987042000268512 Acesso em 30/06/2021 >. 
vivência religiosa, onde: "[...] sujeitos brancos adquirem consciência dos privilégios da branquitude, da estrutura racista, da sociedade e como negociam sua branquitude" (Lia SCHUCMAN, 2020, p. 188). É na vivência cotidiana no ilê, e obtendo conhecimentos sobre religiões de matriz africana, e mais especificamente do candomblé, que me aparece como desafio a construção de um conjunto de práticas, derivadas de uma percepção individual que precisa responder à minha condição de branquitude de maneira crítica e produzir novos sentidos para a experiência de aprendizado da/na religião, percebendo-me como racializada e, portanto, necessitada da vivência comunitária: “Aqui é importante frisar que o que possibilita essa vivência não é a experiência positiva com o outro, mas sim o deslocamento de si para uma outra posição subjetiva, de perceber a alteridade nem como inferior nem como superior [...] (Lia SCHUCMAN, 2020, p. 191).

O candomblé é um espaço religioso que possibilita o letramento racial a partir de uma mediação que leva em conta as relações de afeto não hierarquizadas racialmente, promovendo assim um deslocamento de si (pessoa branca), para uma posição de se colocar no lugar do/a outro (pessoa negra) e retornar a voltar a olhar para si como pertencente a um grupo racial:

"São as relações com os significados construídos por sujeitos negros pela estética negra ou pelo esforço de organizações negras, que determinam as percepções e a sensibilidades sociais da ideia de raça [...] é preciso que a branquitude como lugar de normatividade e poder se transforme em identidades étnico-raciais brancas, nas quais o racismo não seja o pilar de sua sustentação" (Lia SCHUCMAN, 2020, p. 194 e 196).

É importante reforçar novamente que, mesmo que as epistemologias de terreiro ${ }^{12}$ e a vivência em comunidade possibilitem o processo de letramento racial, essa não é uma obrigação destes espa-

Dinâmicas educativas que potencialmente ressignificam e rearticulam as relações entre corpo, mente, espiritualidade, transcendência, vida, conhecimento, teoria e prática. Disponível em: < https://unilab.edu.br/2019/12/05/epistemologias-dos-terreiros-discute-movimentos-sociais-e-educacao-como-espaco-de-construcao-de-conhecimentos >. Acesso em 11/10/2021. 
ços e nem das pessoas negras que ali compõem aquele espaço. Como bem foi colocado nas citações do trabalho de Lia Schucman (2020), o processo de deslocamento deve partir dos sujeitos brancos que se inserem dentro destes espaços religiosos, relacionando-se de maneira não hierárquica com pessoas negras que integram este espaço.

O processo de letramento racial e da intersecção de encruzilhadas que o candomblé tem me proporcionado em tão pouco tempo, tem me possibilitado ter um novo olhar não somente em meus conhecimentos enquanto pesquisadora sobre religião, feminismo e gênero, mas também enquanto corpo branco neste espaço. Não defendo a ideia de que todas as pessoas brancas deveriam frequentar o candomblé para realmente reconhecerem a sua identidade branca enquanto raça, até porque, defendi em vários momentos deste artigo, que esse processo só acontece a partir de um exame responsável de consciência, que impulsione a pessoa branca a questionar a sua identidade. Portanto, frequentar, e até se iniciar no candomblé, não garante que uma pessoa branca se submeta ao letramento racial nesse espaço.

Há outros espaços marcados pela tensão interracial no cotidiano que podem dar o "start" que eu tive quando decidi me iniciar no candomblé, mas não posso deixar de afirmar que as epistemologias de terreiro, por darem corpo aos conceitos, desafiam e desnudam os corpos brancos vestidos de uma colonialidade confortável.

\section{CONSIDERAÇÕES FINAIS}

Através da autoetnográfia, um método qualitativo, crítico e de auto reflexão, onde a experiência pessoal contribui para análises de determinado contexto social, este artigo procurou apresentar uma análise sobre a percepção da minha identidade branca a partir da minha experiência como iniciada há pouco mais de dois anos no candomblé. Reconheço que tal método possui seus limites e que, portanto, não está isento de críticas, o que me leva a considerar a possibilidade de, posteriormente, realizar uma análise mais ampliada sobre a percepção da identidade branca a partir de um campo religioso específico, no caso o candomblé.

A escolha por expor a minha experiência a partir de trechos de um relato em fragmentos se justifica por ser a maneira mais didática que 
encontrei, e que me é mais confortável, de articular um corpo teórico coerente com as informações contidas em cada fragmento, o que facilitou a articulação de análises e reflexões sobre os temas que aparecem no artigo como um todo.

O primeiro tópico apresenta um panorama breve dos estudos sobre branquitude no país e os/as principais intelectuais sobre o assunto até então, trazendo com certo destaque a articulação do conceito de Pacto Narcísico para a análise do fragmento do meu relato no início do tópico em questão. No segundo, abordo o tema do embranquecimento do candomblé distinguindo o mesmo do conceito de branquitude, sem ignorar as possíveis tensões de uma branquitude crítica quando inserida na prática cotidiana do candomblé. Reconhece-se neste tópico a importância da educação de axé, que me levou a reconhecer que possuo uma ancestralidade racista. Outro tema que destaco neste tópico é o que chamo de processo de branqueamento dos orixás de acordo com a noção de hierarquia de importância no panteão, e também de "escurecimento" da ancestralidade branca, que acontece quando pessoas brancas agregam para si a vasta família ancestral negra herdada de seu orixá. O risco de tal processo é o de gerar um não reconhecimento do ser branco como uma identidade racial, o que possui implicações históricas e grande responsabilidade na manutenção do mito da democracia racial em diversos espaços da sociedade.

No terceiro tópico, a partir do fragmento em que me refiro à figura de minha sacerdotisa no candomblé e das Orixás femininas, questiono a "supervalorização" da categoria de gênero para a análise desse contexto, como a expressão de uma branquitude feminina e também feminista, pela insistência no uso impositivo da mesma para analisar uma dinâmica social onde gênero não é um critério de classificação ou/e hierarquização tão relevante, bem como a fixação pela ideia da opressão universal, que é consequência da fixação por gênero, marginalizando a categoria raça. As orixás atribuídas ao feminino, assim como os masculinos, são elementos da natureza vitais para a humanidade na comunidade iorubá. Vale acrescentar que reconheço que no contexto das religiões de matriz africana no Brasil pode haver uma influência da noção de gênero como classificação de poder e influenciar as dinâmicas religiosas. 
O quarto e último tópico começou com o fragmento do meu relato onde falo sobre os tensionamentos que senti da minha experiência religiosa anterior ao candomblé, e que a do individual e do coletivo, foi um dos impulsos que me desafiou a encontrar no candomblé uma oportunidade de receber um letramento racial religioso, o qual acontece a partir de relações de alteridade não hierarquizadas.

Espero que neste artigo eu tenha apresentado minha experiência pessoal de forma responsável e respeitosa para com o candomblé e para com toda a comunidade de adeptos/as. Que eu tenha deixado evidente que o caminho metodológico da autoetnografia pode ser útil e crítico, suscitando reflexões e práticas importantes, sem deixar de considerar seus limites. Espero que a discussão sobre branquitude possa se tornar recorrente dentro das Ciências da Religião, especialmente para os estudos sobre gênero, visto que as mulheres são maioria em diversos espaços religiosos. $\mathrm{E}$, por fim, espero que tenha ficado muito bem explicado que este artigo, em momento algum, reivindica um protagonismo da experiência de mulheres brancas no candomblé, e sim, a explicitação, a partir da minha experiência pessoal, que não é padrão, de tensionamentos interseccionados dentro da minha vivência no candomblé.

\section{REFERÊNCIAS BIBLIOGRÁFICAS}

AMARAL, Rita de Cássia; SILVA, Vagner Gonçalves. A cor do Axé. Brancos e Negros no Candomblé em São Paulo. Estudos Asiáticos, v. 25, 1993, pp. 99-124.

AKOTIRENE, Carla. Interseccionalidade. São Paulo: Pólen, 2019

BENTO, Maria Aparecida da Silva. Pactos narcísicos no racismo: Branquitude e poder nas organizações empresariais e no poder público. Tese. Instituto de Psicologia da Universidade de São Paulo, Departamento de Psicologia da Aprendizagem, do Desenvolvimento e da Personalidade, 2002.

BERGER, Peter. O dossel sagrado: Elementos para uma teoria sociológica da religião. São Paulo: Paulus. 2013.

BERNARDO, Teresinha. O Candomblé e o Poder Feminino. Revista de Estudos da Religião, n. 2, 2005, pp. 1-21.

BOURDIEU, Pierre. Economia das trocas simbólicas. São Paulo. Perspectiva. 2013.

CARDOSO, Lourenço. O branco-objeto: o movimento negro situando a branquitude. Instrumento, v. 13, n. 1, 2011, pp. 81-93. 
CARNEIRO, Sueli. Enegrecer o feminismo: a situação da mulher negra na América Latina a partir da perspectiva de gênero. In. HOLLANDA, Heloísa B. (Org.). Pensamento Feminista: Conceitos Fundamentais. Rio de Janeiro: Bazar do Tempo, 2019, pp. 313-321. RESK, Felipe. Brancos são mais de $60 \%$ dos adeptos de religiões afro-brasileiras em São Paulo. Estadão, 23 de dezembro de 2016. Disponível em: < https://sao-paulo.estadao.com. br/noticias/geral,brancos-sao-maioria-nas-religioes-afro-brasileira-diz-estudo,10000096203 >. Acesso em: 30 mai. 2021.

FRANÇA, Jonas. Elementos para um debate sobre os brancos e a branquitude no candomblé: identidades, espaços e responsabilidades. Revista Calundu, v .2, n. 2, jul-dez, 2018, pp. 55-81.

FERREIRA, J. Flávio. Fazendo gênero no Candomblé: entre o feminismo internacional e a retórica salvacionista. Por um enunciado epistemológico desde os terreiros. Revista Norus, n. 5, v. 4, jan-jun, 2016, pp. 158-181.

GONZALEZ, Lélia. Racismo e Sexismo na cultura brasileira. In: HOLLANDA, Heloísa B. (Org.). Pensamento Feminista Brasileiro: formação e contexto. Rio de Janeiro: Bazar do Tempo, 2019, pp. 237-258

GONZALEZ, Lélia. Racismo por omissão. In: RIOS, Flávia; LIMA, Máricia. Por um feminismo Afro-Latino Americano. Rio de Janeiro: Zahar, 2019, pp. 220-221

HUIJG, Dieuwertje Dyi. Feministas brancas, tirando as máscaras: a expressão da branquitude feminina nas relações raciais intra-gênero. Dissertação. Departamento Línguas e Culturas da América Latina, Faculdade de Letras da Universidade de Leiden, 2007.

KILOMBA, Grada. Memórias da Plantação: Episódios de racismo cotidiano. Rio de Janeiro: Cobogó, 2019.

LANFRANCHI, Marcelo Amaral. Lutero e o sacerdócio universal do crente. Revista REVELETEO - Revista Eletrônica Espaço Teológico, v. 13, n. 24, jul/dez, 2019, pp. 81-99. MARIOSA, Gilmara S.; MAYORGA, Cláudia. Mulheres de tabuleiro/mulheres de terreiro: trajetórias de mulheres negras. Escrita da História, v. 5, n. 9, jan./jun., 2018, pp. 98-118. PICKLES, Matt. 'Selfie acadêmica': Os pesquisadores usam a si mesmos como base de estudos. BBC News Brasil, 28 de maio de 2017. Disponível em: < https://g1.globo.com/ ciencia-e-saude/noticia/selfie-academica-os-pesquisadores-que-usam-a-si-mesmos-como-base-de-estudos.ghtml >. Acesso em 14 jun. 2021.

MATORY, J. Lorand. Feminismo, nacionalismos, e a luta pelo significado do Adé no Candomblé: ou como Edilson Carneiro e Ruth Landes inverteram o curso da história. Revista de Antropologia, v. 51, n. 1, 2008, pp. 107-121.

MULLER, Tânia; CARDOSO, Lourenço (Orgs.). Branquitude: Estudos sobre a identidade branca no Brasil. Curitiba: Apress, 2017.

MENEZES, Nilza. A violência de gênero nas religiões afro-brasileiras. João Pessoa: Editora Universitária da UFPB, 2012. 
O racismo brasileiro na obra de Lélia Gonzalez. Carta Capital. Disponível em: <https:// www.cartacapital.com.br/blogs/sororidade-em-pauta/o-racismo-brasileiro-na-obra-de-lelia-gonzalez/>. Acesso 11 out.2021

OLIVEIRA, Kiusam R. Candomblé e Educação: estratégias para o empoderamento da mulher negra. Tese. Doutorado em Educação. Faculdade de Educação da Universidade de São Paulo, 2008

OYEYUMI, Oyeronké. A invenção das mulheres: construindo um sentido africano para os discursos ocidentais de gênero. Rio de Janeiro: Bazar do Tempo, 2021.

OYEWUMI, Oyeronké. Conceituando Gênero: os fundamentos eurocêntricos dos conceitos feministas e o desafio das epistemologias africanas. In: HOLLANDA, Heloísa B. (Orgs.). Pensamento feminista: perspectivas decoloniais. Rio de Janeiro: Bazar do Tempo. 2020, pp. 84-95.

PIZA, Edith. Porta de vidro: entrada para branquitude. In: CARONE, Iray; BENTO, Maria Aparecida da Silva (Orgs.). Psicologia Social do Racismo: estudos sobre branquitude e branqueamento no Brasil. Petrópolis: Vozes, 2002.

ROSA, Laila. "No terreiro predomina mais a mulher, porque a mulher tem mais carisma": música, gênero, raça, sexualidade e cotidiano no culto da jurema. In: Fazendo Gênero 9: Diásporas, diversidade e deslocamentos, 23 a 26 de agosto de 2010.

RODRIGUES, Denise. Religiosos Sem Igreja: Um Mergulho na Categoria Censitária dos Sem Religião. Revista de Estudos da Religião, ano 7, dezembro, 2007, pp. 31-56.

RODRIGUES, Ozaias da Silva. Do evangelho ao candomblé: a inserção de um pesquisador evangélico nas religiões de matriz africana. Revista Discente Planície Científica, v. 1, n. 1, jan./jul. 2019, s/p.

RUFINO, Luiz. Pedagogia das encruzilhadas: Exu como educação. Revista Exitus, v. 9, n. 4, Out/Dez, 2019, pp. 262-289.

'Selfie acadêmica': Os pesquisadores que usam a si mesmos como base de estudos. BBC News Brasil. Disponível em: <https://www.bbc.com/portuguese/geral-40006132>. Acesso em 11 out. 2021.

SANTOS, Silvio Matheus A. O método da etnografia na pesquisa sociológica: atores, perspectivas e desafios. Plural, v. 24, 2017, pp. 214-241.

SCHUCMAN, Lia V. Entre o encardido, o branco, e o branquíssimo: branquitude, hierarquia e poder na cidade de São Paulo. São Paulo: Veneta, 2020.

SPINK, Mary Jane P. Pesquisando no cotidiano: recuperando memórias de pesquisa em Psicologia Social. Psicologia e Sociedade, v. 19, n. 1, 2007, pp. 7-14.

Submetido em: 15-9-2021

Aceito em: 13-11-2021

Mandrágora, v.27, n. 2, 2021, p. 91-113 